\title{
La fe de los insignificantes A Gustavo Gutiérrez, en señal de agradecimiento, aprecio y amistad
}

\author{
Víctor Codina, S.J. \\ Universidad Católica Boliviana, \\ Centro de Espiritualidad Ignaciana, \\ Cochabamba, Bolivia.
}

\section{Breve memoria de un camino ya recorrido}

Desde Medellín (1968) forma parte de la tradición teológica latinoamericana el hablar de los pobres como de un lugar teológico y hermenéutico privilegiado.

Para comprender correctamente esta afirmación, que para algunos todavía resulta sorprendente, basta recordar que ya en el siglo XVI el teólogo Melchor Cano (1509-1560) en su célebre tratado sobre los lugares teológicos (Loci theologici) distinguía entre lugares teológicos mayores o fundamentales (la Escritura, la Tradición que expresa el sentido de fe de la Iglesia interpretada por los Concilios, el magisterio y los teólogos) y lugares teológicos complementarios o derivados (la razón natural, la filosofía y los acontecimientos históricos). Estos lugares teológicos complementarios a lo largo del tiempo han ido tomando mayor relieve y concreción: la liturgia, el arte y los iconos, las Iglesias locales, los signos de los tiempos. Y en América Latina, los pobres.

No se trata, en el caso de América Latina, de sustituir los lugares teológicos fundamentales por los complementarios, sino de leer e interpretar la fe y la tradición de la Iglesia desde este lugar hermenéutico privilegiado que son los pobres ${ }^{1}$. No se

1. Varios, Comentario a la "Notificación" sobre Jon Sobrino, Cuadernos de Cristianisme i Justícia 148, Barcelona, 2007; J. I. González Faus, "Los pobres como lugar teológico", Revista Latinoamericana de Teología 3 (1984) 275-308. 
pretende ninguna canonización del pobre como universal negativo marxista, sino de elaborar una lectura teológica de la Escritura. Los pobres son pecadores, como todos nosotros, pero por ser pobres y oprimidos son objeto del amor y la benevolencia divina. El fundamento de esta prioridad no es, pues, antropológico: la santidad del pobre, sino teológico: se basa en la psicología de Dios, el corazón tierno y compasivo del Señor que no quiere ver sufrir a la humanidad y se indigna ante la injusticia que provoca pobres y que rompe su proyecto de vida para todos, el Reino de Dios (Puebla 1142).

El Éxodo ${ }^{2}$, la praxis evangélica de Jesús de Nazaret y su identificación con los pobres en la parábola del juicio final (Mt 25, 31-46) ${ }^{3}$, fundamentan este lugar privilegiado de los pobres en la Iglesia y la teología. Su situación de empobrecimiento y de víctimas nos desinstala y nos llama a la conversión y a la solidaridad. Son los crucificados de este mundo a los que hay que bajar de la cruz ${ }^{4}$. Son los vicarios de Cristo, en expresión medieval ${ }^{5}$.

Tanto Medellín y Puebla, como la teología de la liberación, que tanto debe a Gustavo Gutiérrez, han intentado leer la fe de la Iglesia desde los pobres. Esto ha conducido a la metodología del ver, juzgar y actuar, al uso de las mediaciones socio-analíticas, hermenéuticas y práxicas, que ha derivado en la opción evangélica y preferencial por los pobres (Puebla 1134-1164), que el mismo Benedicto XVI ha afirmado que está implícita en nuestra fe cristológica (Aparecida 392). Esta opción por los pobres, que se formuló desde la Iglesia de América Latina, hoy ha pasado a ser patrimonio de la Iglesia universal, como el mismo Juan Pablo II expresó (TMA 51).

Con el paso de los años, en América Latina la situación de la pobreza, lejos de mejorar, se ha agravado en los últimos tiempos, y siempre resulta inquietante la pregunta de G. Gutiérrez "dónde dormirán hoy los pobres". La opción por los pobres continúa siendo actual y urgente.

Esta opción por los pobres, que al principio tal vez tuvo un cierto tinte preponderantemente social, se integró en una visión más global: evangelizar a los pobres. Evangelizar a los pobres constituye un signo mesiánico (Mt 11, 5; Lc 7, 22), como el mismo Vaticano II lo recordó (LG 8). Pablo VI declaró que la evangelización está estrechamente ligada a la liberación y a la promoción humana (EN 31). Evangelizar a los pobres no equivale simplemente a enseñarles el catecismo, sino que implica un compromiso por un Reino de justicia y solidaridad.

2. Cfr. L. C. Susin (ed.), El mar se abrió. Treinta años de Teología en América Latina, Santander, 2001.

3. X. Pikaza, Hermanos de Jesús y servidores de los más pequeños (Mt 25, 31-46), Salamanca, 1984.

4. Comisión Teológica Internacional, Bajar de la cruz a los pobres, México, 2007.

5. J. I. González Faus, Vicarios de Cristo, Madrid, 1991. 
También Gustavo Gutiérrez se ha preocupado sobre cómo evangelizar a los pobres, cómo hablar de Dios a los que sufren ${ }^{6}$.

De esta opción por los pobres, del compromiso liberador y del deseo de evangelizarlos surge una espiritualidad profundamente enraizada en América Latina: una espiritualidad de la liberación, el ser contemplativos en la liberación, el beber en el propio pozo del pueblo, una fuente regada por sus lágrimas y por su misma sangre ${ }^{7}$.

Todo esto es ya conocido y ha sido ampliamente estudiado. Basta recordarlo brevemente para poder avanzar un poco más.

\section{De una Iglesia para los pobres a la Iglesia de los pobres}

Tanto la opción por los pobres como el esfuerzo por evangelizarlos, por nobles y necesarios que sean, no dejan de considerar a los pobres como objeto de la solidaridad y de la evangelización de la Iglesia. Se opta por un sector de la Iglesia, al que se desea liberar y evangelizar. Pero podemos preguntarnos si no podemos dar un paso más. Cuando Juan XXIII un mes antes del Vaticano II, el 11 de septiembre de 1962, habló de la Iglesia de los pobres, seguramente entrevió una Iglesia en la cual los pobres no solo eran objeto de compromiso y evangelización para la Iglesia, sino sujeto de configuración eclesial.

En esta línea se debe interpretar lo que el magisterio latinoamericano afirma sobre el potencial evangelizador de los pobres y la dimensión evangelizadora de las comunidades de base (Puebla 1147). Todos los que han ido a compartir la vida de los pobres y se han insertado en medio de ellos afirman que los pobres les han evangelizado. El obispo Pedro Casaldáliga, en su poema sobre monseñor Romero, acaba diciendo: "Los pobres te enseñaron a leer el evangelio".

Gustavo Gutiérrez siempre ha afirmado que América Latina es un continente oprimido y cristiano. Tal vez hasta ahora hemos considerado más su dimensión sociológica de pobreza que su condición de cristiano. ¿Qué nos aportan los pobres que son de tradición cristiana a la Iglesia en su conjunto?

Para enfocar el problema podemos partir de las afirmaciones del Vaticano II sobre el sentido de la fe del pueblo cristiano, que tiene la unción del Espíritu ( $1 \mathrm{Jn} 2,20.27)$ y es infalible en su creencia cuando se adhiere con toda la Iglesia a la fe que ha recibido (LG 12).

Los comentaristas de este texto del Vaticano II recalcan la importancia de este sensus fidelium, del sentido sobrenatural de la fe, que no es simplemente la obediencia al magisterio, sino que es una captación lúcida de la fe, una especie

6. G. Gutiérrez, Hablar de Dios desde el sufrimiento del inocente, Salamanca, 2001.

7. G. Gutiérrez, Beber en su propio pozo, Lima, 1983. 
de intuición o instinto sobrenatural, una recepción activa del misterio de la salvación. Es lo que Santo Tomás llama conocimiento por connaturalidad ${ }^{8}$, gracias al cual la persona instintivamente se inclina a adherirse a lo que está en armonía con el verdadero significado de la palabra de Dios. La fe reconoce espontáneamente su objeto?.

Los autores suelen poner algunos ejemplos de este sensus fidelium. A Newman le impresionaba mucho que la fe del pueblo cristiano en el siglo IV se hubiera mantenido en la ortodoxia a pesar de que muchos obispos cayeron en la herejía arriana. Hilario de Poitiers, por su parte, decía que los oídos de los fieles son más santos que los labios de los sacerdotes, es decir el pueblo interpreta correctamente aun aquellas verdades que no están bien formuladas por la boca de sus sacerdotes ${ }^{10}$.

Pero todos estos autores y el mismo Vaticano II nade dicen respecto de la fe de los pobres. La pregunta que podemos hacernos es la siguiente: dentro del pueblo de Dios creyente, ¿la fe de los pobres no tiene alguna especial significación o importancia que pueda justificar las afirmaciones de que los pobres evangelizan y poseen un potencial evangelizador?

\section{Los insignificantes}

Llama poderosamente la atención que el texto lucano conocido como "la exultación mesiánica" de Jesús no haya sido suficientemente profundizado ni se haya tomado en cuenta en el contexto de una teología de los pobres.

Según Lucas 10, 21-22, Jesús, lleno de gozo en el Espíritu Santo, bendice al Padre por haber ocultado estas cosas a los sabios e inteligentes y haberlas revelado a la gente sencilla (nepioi). Y esta exultación y alabanza acaba con una confesión de la misteriosa e íntima relación entre el Padre y el Hijo: nadie conoce al Hijo sino el Padre y nadie conoce al Padre sino el Hijo y aquel a quien el Hijo se lo quiera revelar ${ }^{11}$.

8. Suma Teológica II a IIae, 2, 2, ad 2. La persona casta, dice Tomás, conoce por connaturalidad todo lo que corresponde a esta virtud y todo lo que la pone en peligro.

9. J. M. R. Tillard, Église d'Églises, París, 1987, p. 145; cfr. del mismo J. M. R Tillard, Le Sensus fidelium, refléxion théologique, Foi populaire et foi savante, París, 1976.

10. I. Ruidor, Iglesia de Dios, Iglesia de los hombres, Vol. I, Zaragoza-Santander, 1972 , pp. 71-72.

11. Puede verse una comentario exegético de este texto en J. A. Fitzmyer, El evangelio según Lucas, III, Madrid, 1987, pp. 244-264. Puede verse el paralelo de Mt 11, 25-27, que no dice nada sobre la exultación mesiánica de Jesús al pronunciar estas palabras. 
Un texto tan solemne y profundo, con claras resonancias trinitarias, que Lucas coloca después de la misión de los setenta y dos discípulos, merecería un mayor comentario. En esta perícopa se contraponen los sabios y prudentes, es decir los doctores de la ley que no comprenden el misterio de Jesús ni su evangelio, a los sencillos a quienes el Padre les ha revelado los misterios del Reino. La palabra griega nepioi, significa literalmente la gente pequeña, que no puede hablar, infantil, inmadura y en este contexto se aplica a los discípulos que son gente sencilla y sin preparación ni estudios.

Podríamos decir que nepioi se refiere a la gente sin importancia, que no cuenta, que no sabe ni puede, el grupo de personas que en América Latina E. Galeano llama "los nadies" y Gustavo Gutiérrez califica como "insignificantes". Podemos, pues, traducir los nepioi por insignificantes, que incluye a pequeños, ignorantes, pobres, mujeres, indígenas y afroamericanos, ancianos, excluidos y marginados sociales...los que no significan nada para los grandes y poderosos de este mundo. Son los mismos a los que Pablo llama débiles, plebeyos, despreciables, locos a los ojos del mundo, pero que han sido escogidos por Dios para confundir a los sabios y poderosos de este mundo (1 Cor 26-31).

No se trata aquí de afirmar una superioridad moral de la gente sencilla e insignificante, sino de reconocer la acción benevolente y gratuita de Dios que ha querido revelarse a este grupo de personas. Jesús bendice al Padre por su designio amoroso, no por las virtudes de los pobres, muchas veces inexistentes. En los evangelios podemos encontrar muchos ejemplos de esta revelación del Padre a los sencillos e insignificantes.

El anuncio del nacimiento de Jesús en Belén se comunica a unos pastores desconocidos e insignificantes, mal vistos por el pueblo, quienes regresan alabando a Dios por todo lo que habían visto (Lc 2, 8-29). El anciano Simeón y la profetisa Ana descubren al Mesías prometido, luz de las gentes, en aquel niño que una pareja de campesinos pobres presentan al templo, mientras que los sacerdotes, escribas y fariseos allí seguramente presentes, no captan el misterio de la entrada de la gloria del Señor en el santuario (Lc 2, 22-38).

La profesión de fe de Pedro, que no se debe a la carne y sangre, sino a la revelación del Padre (Mt 16, 13-20 y paralelos), puede ser otro ejemplo claro de esta fe de la gente sencilla e insignificante, una profesión de fe sobre la que se fundamentará la fe de toda la Iglesia del futuro y una fe que no protege a Pedro de la ignorancia ni de sus futuras caídas. Pedro-roca es llamado luego piedra de escándalo y Satanás (Mt 16,23), para que nadie se gloríe en sí mismo, sino en el Señor, como dice Pablo (1 Cor 1,31).

Aplicando todo cuanto hemos visto antes al sentido de la fe del pueblo (LG 12), la de los pobres y sencillos, podemos afirmar que el Espíritu les confiere a ellos una especial connaturalidad con el Reino de Dios, les abre los ojos 
del corazón para que puedan comprender lo que los sabios, que se fían de su propia sabiduría, no logran captar. Esto explica por qué el pueblo sencillo de Galilea sintonizó con Jesús, mientras los escribas y fariseos y los sacerdotes lo rechazaron. Los pobres comprenden con facilidad que el Reino es un proyecto de vida y de justicia que se opone a la idolatría del dinero, de Mamón, que es la causa de los males y de la pobreza del pueblo (Mt 6, 24).

Como afirma desde Asia A. Pieris, Dios y los pobres han establecido una alianza para la realización del Reino de Dios, que implica una batalla contra el enemigo común concreto: Mamón, el ídolo de la riqueza. Allí donde se ama y se sirve a Dios, son los pobres y no la pobreza los que reinan; allí donde se ama y se sirve a los pobres, es Dios y no Mamón quien reina ${ }^{12}$.

Por esto los pobres son llamados bienaventurados y a ellos se les promete el Reino, no por ser mejores, ni porque el sufrimiento sea bueno y así merezcan el cielo, sino porque ellos son los que comprenden el misterio del Reino gracias a la revelación del Padre y ellos son los destinatarios privilegiados de este proyecto del Padre que Jesús revela.

\section{Confirmación latinoamericana}

A la pregunta de Gustavo Gutiérrez "dónde van a dormir los pobres", podemos añadir otro interrogante: ¿por qué no se suicidan los pobres, sino que luchan por la vida, se casan, tienen hijos, esperan un mañana mejor, compran flores y celebran fiestas? La respuesta es profunda y sencilla al mismo tiempo: el Señor que les revela los misterios del Reino, suscita en ellos una gran esperanza, sienten que "Diosito" siempre les acompaña.

Desde la población mayoritariamente pobre, sencilla e insignificante de América Latina y el Caribe, se puede comprender la distinción de la vieja escolástica entre la fides quae y la fides qua. La fides quae son los contenidos de la fe, que para el pueblo sencillo muchas veces son muy pobres y limitados. La fides qua es la actitud creyente, la gran confianza en Dios que poseen. El pueblo sencillo de América Latina, los insignificantes, aunque posean unos contenidos teológicos de la fe limitados, tienen una gran fe y una gran esperanza en Dios; por esto el pueblo no se suicida colectivamente, siente por connaturalidad que Dios está de su parte.

Podemos considerar tres expresiones concretas de la fe de los insignificantes en América Latina: la religiosidad popular, la lectura popular de la Biblia y las comunidades de base.

12. A. Pieris, El Reino de Dios para los pobres de Dios. Retorno a la fórmula de Jesús, Bilbao, 2006, p. 52. 
La fe y religiosidad popular permanecen vivas en América Latina y el Caribe como en el documento de Aparecida se afirma continuamente: es el precioso tesoro de la Iglesia católica, refleja la sed de Dios que solo los pobres y sencillos reconocen (Aparecida 258; 549), profesa su fe en el Dios cercano a los pobres, cree en el Dios de la compasión, del perdón y la reconciliación, en el Cristo sufriente, en el Señor presente en la eucaristía, tiene una profunda devoción a la Virgen María en sus diversas advocaciones, su fe está presente en la lucha por la justicia, espera contra toda esperanza, posee la alegría de vivir aun en condiciones muy difíciles (Aparecida 7). Esta fe se manifiesta en muchas expresiones populares: en el arte de imágenes y santos, fiestas y tradiciones, danzas religiosas, procesiones, peregrinaciones a santuarios, vía crucis, promesas, oraciones en familia (Aparecida 262). En esta fe hay una experiencia teologal, una sabiduría sobrenatural, una verdadera espiritualidad encarnada en la cultura de los sencillos (Aparecida), en una síntesis de fe cristiana y culturas (Aparecida 264). Es una expresión del sensus fidelium (LG 12) de los pobres.

Sin embargo, también Aparecida reconoce que una fe reducida a prácticas de devoción fragmentadas, a participación ocasional de los sacramentos, a repetición de principios doctrinales y morales, poco a poco se erosiona y no resistirá a la larga el embate del tiempo (Aparecida 12).

Por esto Aparecida insiste en pasar de una pastoral conservadora a otra misionera, pues estamos en estado de misión (Aparecida 370), hay que ofrecer al pueblo creyente una mayor formación cristiana.

Aquí aparece la importancia de todo el gran esfuerzo que se está haciendo para devolver la Biblia a los pobres, para iniciar a una lectura popular de la Biblia, para que la gente sencilla, los insignificantes, puedan leer la Escritura. Los pobres y sencillos tienen una gran connaturalidad con la Escritura, la sienten suya, es su historia, el espejo de su propia vida. La comprenden mejor que otros sectores sociales, que quizás tienen más conocimientos y mayor erudición, pero menos sintonía con el fondo del mensaje bíblico y evangélico. Los círculos bíblicos, la metodología inspirada en C. Mesters, la lectura orante de la Biblia, en estrecha conexión con la vida del pueblo (el pre-texto), ofrecen a la gente sencilla un alimento que nutre su religiosidad popular e ilumina su fe con una esperanza inquebrantable de que el Señor les acompaña siempre, como acompañó al Pueblo de Israel y a la primitiva Iglesia. Nuestros hermanos evangélicos pueden ser para nosotros un modelo de esta preocupación por iniciar al pueblo sencillo en el conocimiento de la Palabra de Dios.

Muchas veces de estos grupos bíblicos nacieron comunidades de base, expresión de la fe eclesial del pueblo sencillo, de los insignificantes. Aunque en Aparecida se oyeron voces que querían minimizar las comunidades eclesiales de base por considerarlas sospechosas y preferían potenciar los nuevos movimientos y las pequeñas comunidades que surgen en torno a otros sectores sociales, 
las comunidades eclesiales de base fueron reafirmadas como expresión visible de la opción de la Iglesia por los pobres, fuente y semilla de variados ministerios y servicios a favor de la vida en la sociedad y en la Iglesia, signo de vitalidad de la Iglesia particular, despliegan su compromiso evangelizador y misionero (Aparecida 179). Son, podemos afirmar, una realización de la Iglesia de los pobres que Juan XXIII soñó antes del Vaticano II.

El ideal es que la religiosidad popular se vaya enriqueciendo con la Palabra y se puedan ir constituyendo comunidades eclesiales de base que sean foco de evangelización y promoción social.

\section{A modo de conclusión}

$\mathrm{Si}$ asumimos todo este camino recorrido y tomamos en serio la exultación mesiánica de Jesús sobre la revelación de los misterios del Reino a los pobres, podemos reafirmar que los pobres constituyen realmente un lugar teológico y hermenéutico privilegiado para la Iglesia de América Latina y el Caribe.

Pero deberíamos sacar algunas consecuencias de todo ello. La Iglesia como comunidad, ¿escucha a los insignificantes?, ¿se deja evangelizar por ellos?

Los pastores iescuchan a los insignificantes del pueblo cristiano antes de hablar y enseñar como maestros auténticos de la verdad (LG 25)? No hay ciertamente contradicción entre el magisterio y el sensus fidelium, ambos deben complementarse, sin que haya ruptura y división entre la Iglesia docente y la discente, conspirando todos hacia el bien de la comunidad, pues entre ellos hay una misma comunión, suscitada por el mismo Espíritu de verdad. Pero si los pastores escucharan más a los insignificantes, como hacía Jesús, seguramente sus enseñanzas doctrinales y morales serían más comprensibles y mejor asimiladas por la gente sencilla, habría auténtica recepción de ellas. ¿Conocen y entienden los insignificantes las enseñanzas del magisterio de la Iglesia, que parecen estar más dirigidas a los sabios y letrados de la Iglesia que a la gente sencilla?

La teología ¿escucha a los insignificantes sabiendo que son un lugar de revelación privilegiado, o prefiere escuchar lo que escriben los sabios y doctores, muchas veces muy alejados de la gente sencilla? La fe de los insignificantes no elimina la exigencia de una teología académica y científica, con tal que ésta se nutra de la fe del pueblo y beba en su propio pozo.

Los agentes pastorales ¿parten de la connaturalidad de los insignificantes con el mensaje evangélico, de su fe, de su adhesión instintiva a la Palabra o intentan adoctrinarlos desde arriba como si fueran unos necios ignorantes? ¿Están realmente más preparados para recibir los sacramentos de la iniciación cristiana y los restantes sacramentos de la Iglesia los fieles de los sectores acomodados de la sociedad, que conocen bien la doctrina cristiana, han sido alumnos de colegios católicos privados, pero viven en un ambiente de abundancia y consumismo 
lejos del Reino, que los insignificantes y sencillos que conocen tal vez poco de la doctrina cristiana pero tienen una gran connaturalidad con los valores del Reino, que el Padre les reveló y de ello se alegró Jesús?

Acabemos con una poesía de Casaldáliga, el obispo que vive entre los insignificantes de América Latina:

\author{
El Espíritu \\ ha decidido \\ administrar \\ el octavo sacramento: \\ ¡la voz del Pueblo! $!^{13}$
}

13. P. Casaldáliga, Cantares de la entera libertad, Managua, 1984, p. 73. 